\title{
Evaluating the Accuracy of Net Present Value and Initial Rate of Return Investment Rules
}

\author{
Zhen Wang
}

\author{
The Australian National University \\ u7237023@anu.edu.au
}

\begin{abstract}
The purpose of this paper is to compare the accuracy of two investment decision-making methods, Net present value (NPV) and Internal rate of return (IRR), using four different hypothetical investigations, and to briefly assess the limitations of the NPV method. The use of the IRR rule results in incorrect judgments in four situations: delayed investment, multiple IRRs, no IRRs, and mutually exclusive projects (different scales). However, the judgment method shows the sensitivity of the investment decision to the uncertainty of the cost of capital estimation in the case of delayed investment and two IRRs.
\end{abstract}

Keywords: Net present value; Internal rate of return; Delayed investment; Multiple IRRs; No IRRs; Mutually exclusive projects.

\section{INTRODUCTION}

Nowadays, investors often use the net present value approach or the initial rate of return approach in their daily investment decisions. But IRR rules may lead to erroneous decisions.

Based on the discounted cash flow model, two different methods of net present value and internal rate of return are compared to evaluate the accuracy of investment decisions. They are used in four different scenarios: investment delay, multiple IRRs, no IRRs, and mutually exclusive projects (different scales). It is worth noting that making an investment decision is a simple calculation of the results to determine the feasibility of the project and focuses on cash flow forecasting and depreciation rate estimation. But forecasting cash flows and estimating depreciation rates are the most difficult ones due to future economic conditions are impossible to predict [1].

The purpose of this paper is to compare the accuracy of two investment decision-making methods in order to provide a more secure and accurate method for investors to make investment decisions.

\section{NPV AND IRR INVESTMENT RULES}

Net present value is a financial analysis technique that is predicated on the concept of the time value of money [2]. By predicting future cash flows and depreciation rates, a series of future cash flows are discounted back to today. If NPV is greater than zero, a project will be invested. One interpretation of the internal rate of return is the average return earned through investment opportunities [1]. The IRR investment rules are predicated on the premise that if the average return of the investment exceeds the required rate of return of the project, the investment should be made.

Next, four different hypotheses will be used to test the two methods to determine the accuracy of investment.

\section{DELAYED INVESTMENT}

\subsection{Assumption}

Assume that there is an investment opportunity that will receive a one-time income of $\$ 1,000,000$ at the beginning of the project and requires annual expenses of $\$ 500,000$, and that the project lasts for three years. The opportunity cost of this project is $10 \%$.

\subsection{Calculation}

The first step should be to determine the cash flow of the project, based on the assumption that the cash flow in year 0 is $\$ 1,000,000$ and the cash flow in years 1 through 3 is $-\$ 500,000$. In addition, in order to calculate the net present value and internal rate of return we need to use the following two formulas. 


$$
\begin{gathered}
N P V=\sum_{t=1}^{n} \frac{C F_{t}}{(1+r)^{t}}+C F_{0} \text { Eq. } 1 \\
N P V=\sum_{t=1}^{n} \frac{C F_{t}}{(1+r)^{t}}-C F_{0}=0 \text { Eq. } 2
\end{gathered}
$$

The calculated NPV is $-\$ 243,426$ and the IRR is $23.38 \%$. Using the NPV rule, it was determined that investing in this project would result in a loss of wealth for investors at a discount rate of $10 \%$, and thus should avoid investing in this project. When the IRR rule is applied, it is determined that the IRR exceeds the discount rate, indicating that the project should be invested.

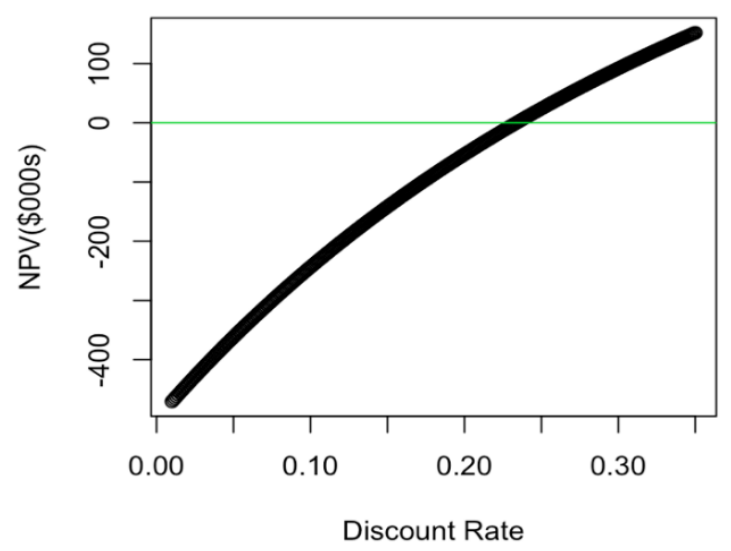

Figure 1: Delayed Investment

Figure 1 illustrates the two rules give completely opposite interpretations. Regardless of the cost of capital, the IRR and NPV rules provide the exact opposite advice. That is, the NPV is positive only if the opportunity cost of capital is higher than $23.38 \%$ (IRR). In fact, for most investment projects, the costs are incurred initially and then the cash is received. However, in this case, the investor borrows money and then exchanges it for future liabilities using the money received today. In this case, the IRR is best interpreted as the investor paying interest rather than income. Although IRR does not provide the correct answer in this case, it reveals how sensitive the investment decision is to the uncertainty associated with the cost of capital estimate [3].

\section{MULTIPLE IRRs}

\subsection{Assumption}

Assume there is an investment opportunity that will receive a one-time income of $\$ 550,000$ at the beginning of the project, a $\$ 500,000$ fee that must be paid at the end of each of the first through third years, and an additional $\$ 1,000,000$ at the end of the fourth year. The opportunity cost of this project is $10 \%$.

\subsection{Calculation}

The first step should be to determine the cash flow of the project, based on the assumption that the cash flow in year 0 is $\$ 550,000$ and the cash flow in years 1 through 3 is $-\$ 500,000$. In year four, the cash flow is $\$ 1,000,000$. Additionally, the net present value and internal rate of return are calculated by formulas $(\operatorname{Eq}(1),(2))$.

The calculated net present value is $-\$ 10,412$. IRR was determined by setting NPV to zero. There are two IRRs in this case: $7.164 \%$ and $33.673 \%$. Use Figure 2 to illustrate the issues that arise in this case as a result of the IRR rule.

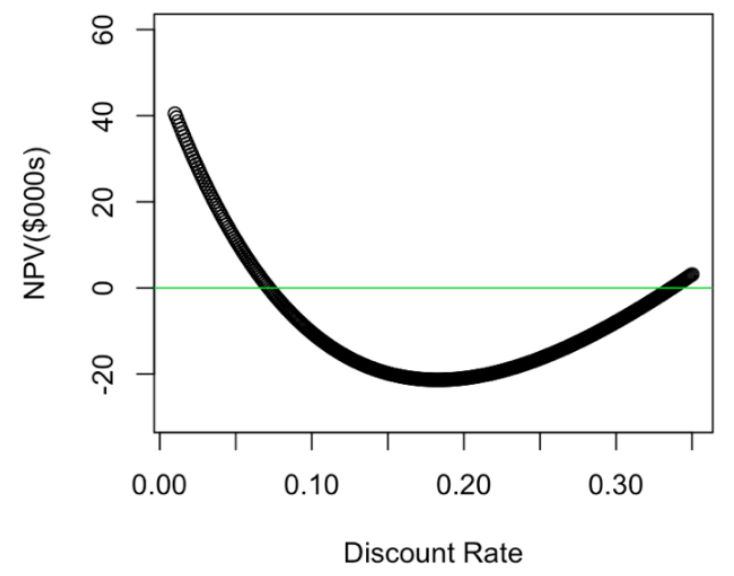

Figure 2: Multiple IRRs

In this case, the NPV is zero due to the presence of two IRRs. Due to the fact that two IRRs violate the IRR judgement principle, the IRR rule cannot be used to make a determination [5]. To illustrate the judgment criteria more broadly, the NPV rules will be referred to. According to Figure 2, which illustrates the NPV overview, investors should invest in a project if the cost of capital is less than $7.164 \%$ or greater than $33.673 \%$; otherwise, the project will be rejected. While the IRR rule cannot be used in this case, the two thresholds define the critical range; that is, when the investor is convinced that his cost of capital is within the range defined by the two thresholds, the investor has sufficient confidence to reject the investment.

\section{NON-EXISTANT IRR}

\subsection{Assumption}

Assume there is an investment opportunity that will receive a one-time income of $\$ 750,000$ at the beginning of the project, a $\$ 500,000$ fee that must be paid at the end of each of the first through third years, and an additional $\$ 1,000,000$ at the end of the fourth year. The opportunity cost of this project is $10 \%$. 


\subsection{Calculation}

The first step should be to determine the cash flow of the project, based on the assumption that the cash flow in year 0 is $\$ 750,000$ and the cash flow in years 1 through 3 is $-\$ 500,000$. The cash flow in year 4 is $\$ 1,000,000$. In addition, in order to calculate the net present value and internal rate of return must be calculated by formulas $(\operatorname{Eq}(1),(2))$.

The NPV can be calculated as $\$ 1,308,670$ by substituting assumptions into the formula, but there is no IRR in this case because the NPV is positive at all discount rates, and thus we cannot use the IRR rule to make a decision. Additionally, Figure 3 illustrates the NPV based on this assumption, and it can be seen that the curve does not intersect the $\mathrm{X}$-axis, indicating that there is no IRR.

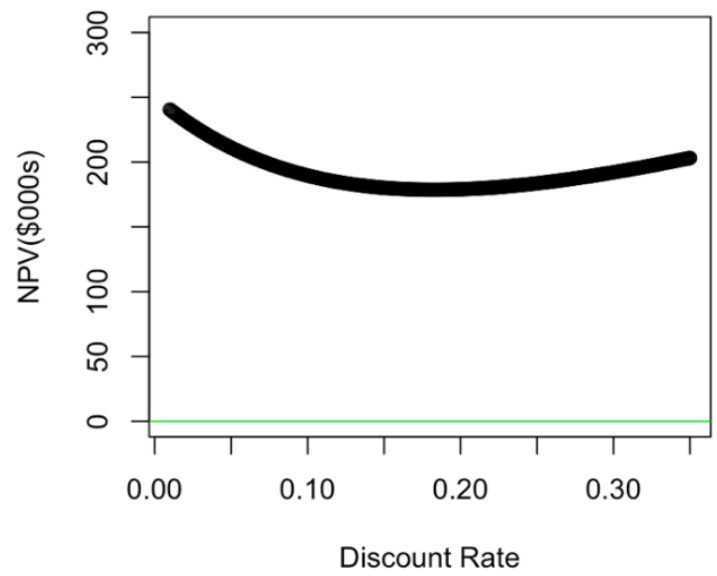

Figure 3: Non-existent IRRs

\section{MUTUALLY EXCLUSIVE PROJECTS (DIFFERENT SCALE)}

\subsection{Assumption}

Assume there are two investment opportunities. The first one is that the project will require a one-time initial investment of $\$ 300,000$ at the beginning of the project. Year 1 cash flow is $\$ 63,000$, and the project cash flow will increase by $3 \%$ in perpetuity. The second one is that the project will require a one-time initial investment of $\$ 400,000$ at the beginning of the project. Year 1 cash flow is $\$ 80,000$, and the project cash flow will increase by $3 \%$ in perpetuity. The opportunity cost of both projects is $8 \%$.

\subsection{Calculation}

The first step should be to determine the cash flow for each project, based on the assumption that the cash flow for the first project in year 0 is $-\$ 300,000$ and the cash flow in year 1 is $\$ 63,000$, and the project cash flow will increase by $3 \%$ in perpetuity. The cash flow for the second project in year 0 is $-\$ 400,000$ and the cash flow in year 1 is $\$ 83,000$, and the project cash flow will increase by $3 \%$ in perpetuity. In addition, in order to calculate the net present value and internal rate of return we need to use the following two formulas.

$$
\begin{gathered}
N P V=C F_{0}+\frac{C F_{1}}{r_{e}+g} \text { Eq.3 } \\
I R R=\frac{C F_{1}}{-C F_{0}}+g \text { Eq.4 }
\end{gathered}
$$

The calculated first project NPV is $\$ 960,000$ and the IRR is $24 \%$. The second project NPV is $\$ 1,200,000$ and the IRR is $23.75 \%$. The calculation shows that the NPV of the first project is smaller than the NPV of the second project, but the IRR Rule gives the exact opposite result. In detail the IRR of the first project is larger than the IRR of the second project.

The IRR rule and the NPV rule give different options when it comes to mutually exclusive investment situations. Since the IRR rule measures the expected return of a project, the IRRs of two projects cannot be meaningfully compared when they present different investment scales. Simply comparing IRR without knowing the initial investment scale will result in investors not being able to judge the value created by the actual investment and making the wrong decision. Therefore, the IRR rule cannot be used to compare investments of different scales. According to the above calculation, the IRR of both projects exceeds the opportunity cost of the project. However, even though the second project has a lower IRR, it generates a higher NPV due to its larger investment size, and therefore the second is more valuable. Investors should choose to invest in the second project.

\section{LIMITATIONS OF NPV}

For a long period of time, many businesses preferred to use NPV to determine the feasibility of their projects because it is a more straightforward and reliable method than other methods. There is no denying that NPV is not perfect, as traditional methods of capital investment analysis do not fully capture the impact of technology change decisions [5]. It has been argued that the projectlevel net present value (NPV) framework places great emphasis on short-term financial results and rarely emphasizes issues that are difficult to quantify, such as quality improvements or manufacturing flexibility, that major manufacturing breakthroughs do not pass the NPV test. It is also widely acknowledged in the financial literature that pure NPV analysis often ignores the richness of business issues [6].

The general steps for determining the feasibility of an investment project using the NPV rules are summarized in most financial textbooks as (1) calculating the cash flow, (2) calculating the discount rate, (3) calculating the NPV, and (4) making a decision. Typically, steps 1 and 
2 are determined using historical data and future forecasts. Given the impossibility of accurately forecasting future events, such as the coronavirus outbreak, the outcome of this prediction may be highly unstable. The choice of risk-free interest rates is also worthy of attention, especially in the case of the coronavirus outbreak, on how to choose risk-free interest rates more accurately will directly affect investors' decision-making. All these factors can influence decision making and lead to investment failure.

\section{CONCLUSION}

This article compares the accuracy of NPV and IRR rules in four different scenarios and highlights the potential pitfalls of IRR rules when selecting independent projects to accept or reject. When the four scenarios discussed in this article occur, the NPV rules should be followed, but even if the IRR rules are not applicable, IRR is a very useful tool in and of itself. IRR quantifies the average rate of return over the life of an investment and indicates the NPV's sensitivity to the incorrect cost of capital estimates. Thus, while understanding the internal rate of return is beneficial, relying solely on it to make investment decisions is risky.

\section{REFERENCES}

[1] Laux, J. 2011, 'Topics In Finance Part VI - Capital Budgeting', American Journal of Business Education, vol. 4, no. 7, pp. 29-37.

[2] Capstone, and Press Staff Capstone 2003, The Capstone Encyclopaedia of Business: The Most upTo-Date and Accessible Guide to Business Ever, John Wiley \& Sons, Incorporated, New York.

[3] Robison, L.J., Barry, P.J. and Myers, R.J. (2015), 'Consistent IRR and NPV rankings', Agricultural Finance Review, Vol. 75 No. 4, pp. 499-513.

[4] Berk, J, \& DeMarzo, P 2016, Corporate Finance, Global Edition, Pearson Education, Limited, London.

[5] Hayes, R.H. \& Abernathy, W.J. 1980, 'Managing our way to economic decline', Harvard business review, vol. 58, no. 4, pp. 67.

[6] Logue, D.E. \& Tapley, T.C. 1985, 'Performance Monitoring and the Timing of Cash Flows', Financial Management, vol. 14, no. 3, pp. 34. 